\title{
Price and Quantity Competition in a Mixed Duopoly with Emission Tax
}

\author{
Shuichi Ohori \\ Faculty of Informatics, Kansai University, Osaka, Japan \\ Email: ohori@kansai-u.ac.jp
}

Received 28 November 2013; revised 28 December 2013; accepted 4 January 2014

Copyright (C) 2014 by author and Scientific Research Publishing Inc.

This work is licensed under the Creative Commons Attribution International License (CC BY). http://creativecommons.org/licenses/by/4.0/

(c) (i) Open Access

\section{Abstract}

This paper compares price and quantity competition in a mixed duopoly with emission tax; in a mixed duopoly, one public firm competes with one private firm in the market. We find that social welfare is the highest when both the firms simultaneously choose price levels. Then, the optimal emission tax is sufficiently lower than the marginal social damage.

\section{Keywords}

Mixed Duopoly; Price Competition; Quantity Competition; Environmental Policy

\section{Introduction}

In many countries, state-owned enterprises in the energy and manufacturing sectors employed few environmental technologies and thus damaged the environment. This is also observed when environmental policies are imposed on such public as well as private firms. The markets of these public firms affect their production and emissions, and consequently affect the environmental policies of the governments. There are some recent studies on the environmental policies in such markets ${ }^{1}$. However, the previous literature generally assumes the case of the quantity competition. This paper examines the difference between price and quantity competition in a mixed duopoly with emission tax; in a mixed duopoly, one public firm competes with one private firm in the market ${ }^{2}$.

This paper compares the optimal emission tax rates in a mixed duopoly. A number of studies have focused on optimal emission taxes under imperfect competition ${ }^{3}$. Taxing emissions in order to reduce social damage

${ }^{1}$ Refer Bàrcena-Ruiz and Garzòn [1], Beladi and Chao [2], Kato [3], Naito and Ogawa [4], and Ohori [5] [6] for environmental policies in the markets of public firms.

${ }^{2}$ Recent papers that have examined the endogenous choice between price and quantity strategies in a mixed oligopoly include Matsumura and Ogawa [7] and Nakamura [8].

${ }^{3}$ Most of the researchers of environmental economics have long recognized that the optimal emission tax is equal to the marginal social damage cost (a Pigouvian tax) when firms are perfectly competitive, because their marginal abatement cost equals the marginal damage cost However, this is not necessarily true for firms in imperfect competition. Refer Requate [9] for a survey. 
worsens the distortion caused by imperfect competition. Barnett [10], the early contribution to this issue, shows that the optimal emission tax falls short of the marginal social damage cost because the weaker emission tax corrects the distortion in market power caused by imperfect competition.

Previous studies on environmental policies in a mixed oligopoly have focused on their role under privatization. In the case of a single domestic market, Kato [3] considers tradable emission permits, while Bàrcena-Ruiz and Garzòn [1] consider emission tax. Naito and Ogawa [4] compare emission tax with the command-and-control regulation. On the other hand, Ohori [5] investigates the effect of privatization under emission taxes in an international market. While the studies discussed above provide interesting results, they do not consider price-setting oligopolies.

In this paper, four potential combinations are considered: 1) both the firms choose prices, 2) both the firms choose quantities, 3) the public firm chooses price and the private firm chooses quantity, and 4) the public firm chooses quantity and the private firm chooses price. We find that social welfare is the highest under Bertrand competition. Then, the emission tax rate should be sufficiently lower than the marginal social damage cost.

\section{The Model}

Consider a domestic market in which one public firm (Firm 0) and one private firm (Firm 1) compete. Firms 0 and 1 are assumed to produce differentiated substitutable goods for which the inverse demand functions are given as $p_{i}=1-q_{i}-\gamma q_{j}(i=0,1, i \neq j)$, where $p_{i}$ and $q_{i}$ denote firm $i$ 's price and quantity, respectively and the parameter $\gamma \in(0,1)$ indicates the degree of substitutability. For simplicity, one unit of a product causes one unit of emission, which damages the local environment. The firm cannot reduce emission except by reducing output. Total emissions are given by $Q\left(=q_{0}+q_{1}\right)$ and the social damage is given by $D(Q)=\psi Q$, where $\psi>0$ denotes the constant marginal damage cost.

We assume that both firms have identical technologies and linear production costs; the latter is denoted by $c q_{i}$, where $c \in(0,1)$ is the constant marginal cost. Firm $i$ 's profit is denoted by $\pi_{i}=\left(p_{i}-c-t\right) q_{i}$, where $t$ denotes the environmental tax rate. We assume that the solutions are interior $1-c-t>0$ and $1-c-\psi>0$. Following Beladi and Chao [2] and Ohori [6], firm 0 's objective function is defined as the sum of the consumer surplus and the producer surplus (i.e., profits of both the firms) and is given by $\omega=C S+\pi_{0}+\pi_{1}$, where $C S$ denotes consumer surplus. On the other hand, firm 1 aims to maximize its own profit.

The government sets the emission tax rate such that social welfare $W$ is maximized.

$$
W=\omega+t Q-D(Q),
$$

where $t Q$ denotes the tax revenue.

The game is constructed using a two-stage decision-making process. In the first stage, the government sets the emission tax rate such that social welfare $W$ is maximized. In the second stage, the two firms simultaneously choose either price or quantity. The game is solved using backward induction.

\section{Four Potential Situations}

In this section, we discuss four potential situations 1 ) both the firms choose prices ( $p$ - $p$ game), 2) both the firms choose quantities ( $q-q$ game), 3 ) Firm 0 chooses price and Firm 1 chooses quantity ( $p$ - $q$ game), and 4) Firm 0 chooses quantity while Firm 1 chooses price ( $q-p$ game).

\section{p-p game}

We consider the first situation wherein both the firms simultaneously set their respective price levels. Consumer surplus is given by

$$
C S=\frac{p_{0}^{2}+p_{1}^{2}+2(1-\gamma)\left(1-\left(p_{0}+p_{1}\right)\right)-2 \gamma p_{0} p_{1}}{2\left(1-\gamma^{2}\right)} .
$$

The public firm 0 maximizes the sum of producer surplus and consumer surplus $\omega$ while the private Firm 1 maximizes its own profit $\pi_{1}$. Based on the first-order conditions and arranging, the respective reaction functions are given by

$$
R_{0}^{p p}\left(p_{1}\right)=\gamma p_{1}+(1-\gamma)(c+t),
$$




$$
R_{1}^{p p}\left(p_{0}\right)=\frac{1}{2}\left(1-\gamma+\gamma p_{0}+c+t\right) .
$$

From these reaction functions, we obtain the equilibrium prices:

$$
\begin{aligned}
& p_{0}^{p p}=\frac{\gamma(1-\gamma)+(2-\gamma)(c+t)}{2-\gamma^{2}}, \\
& p_{1}^{p p}=\frac{1-\gamma+\left(1+\gamma-\gamma^{2}\right)(c+t)}{2-\gamma^{2}} .
\end{aligned}
$$

By substituting the above equilibrium prices into Equation (1) and using $\mathrm{d} W / \mathrm{d} t=0$, we obtain the equilibrium environmental tax as

$$
t^{p p}=\psi-\frac{\left(1-\gamma^{2}\right)\left(1+\gamma-\gamma^{2}\right)(1-c-\psi)}{5-\gamma-3 \gamma^{2}+\gamma^{3}} .
$$

Since the second term on the right-hand side of the above equation is negative based on the above assumptions, Equation (2) implies that the optimal environmental tax rate is lower than the marginal social damage cost (thus the Pigouvian tax rate).

Using Equation (2), we obtain the following results:

$$
\begin{gathered}
\omega^{p p}=\frac{\left(7+\gamma-7 \gamma^{2}-\gamma^{3}+2 \gamma^{4}\right)\left(3-\gamma^{2}\right)^{2}(1-c-\psi)^{2}}{2(1+\gamma)\left(5-\gamma-3 \gamma^{2}+\gamma^{3}\right)^{2}}, \\
\pi_{1}^{p p}=\frac{(1-\gamma)\left(3-\gamma^{2}\right)^{2}(1-c-\psi)^{2}}{(1+\gamma)\left(5-\gamma-3 \gamma^{2}+\gamma^{3}\right)^{2}}, \\
D^{p p}=\frac{\left(3-\gamma^{2}\right)^{2}(1-c-\psi) \psi}{(1+\gamma)\left(5-\gamma-3 \gamma^{2}+\gamma^{3}\right)}, \\
W^{p p}=\frac{\left(3-\gamma^{2}\right)^{2}(1-c-\psi)^{2}}{2(1+\gamma)\left(5-\gamma-3 \gamma^{2}+\gamma^{3}\right)} .
\end{gathered}
$$

\section{q-q game}

We consider the second situation wherein both the firms simultaneously choose quantities. Consumer surplus is given by

$$
C S=\frac{(1-\gamma)\left(q_{0}^{2}+q_{1}^{2}\right)+\gamma\left(q_{0}+q_{1}\right)^{2}}{2} .
$$

Considering the firms' maximization problems, the respective reaction functions are given by

$$
\begin{aligned}
& R_{0}^{q q}\left(q_{1}\right)=-\gamma q_{1}+1-c-t, \\
& R_{1}^{q q}\left(q_{0}\right)=\frac{-\gamma q_{0}+1-c-t}{2} .
\end{aligned}
$$

From these reaction functions, we obtain the equilibrium quantities:

$$
\begin{aligned}
& q_{0}^{q q}=\frac{(2-\gamma)(1-c-t)}{2-\gamma^{2}}, \\
& q_{1}^{q q}=\frac{(1-\gamma)(1-c-t)}{2-\gamma^{2}},
\end{aligned}
$$


which implies that Firm 0's output is higher than that of Firm 1 in equilibrium; that is, $q_{0}^{q q}>q_{1}^{q q}$.

By substituting the above equilibrium quantities into Equation (1) and using $\mathrm{d} W / \mathrm{d} t=0$, we obtain the equilibrium environmental tax as

$$
t^{q q}=\psi-\frac{(1-\gamma)^{2}(1-c-\psi)}{5-2 \gamma-4 \gamma^{2}+2 \gamma^{3}} .
$$

Since the second term on the right-hand side of the above equation is negative, Equation (3) implies that the optimal environmental tax rate falls short of the marginal social damage cost.

Using Equation (3), we obtain the following equilibrium values:

$$
\begin{gathered}
\omega^{q q}=\frac{\left(7-6 \gamma-2 \gamma^{2}+2 \gamma^{3}\right)(3-2 \gamma)^{2}(1-c-\psi)^{2}}{2\left(5-2 \gamma-4 \gamma^{2}+2 \gamma^{3}\right)^{2}}, \\
\pi_{1}^{q q}=\frac{(1-\gamma)^{2}\left(3-2 \gamma^{2}\right)^{2}(1-c-\psi)^{2}}{\left(5-2 \gamma-4 \gamma^{2}+2 \gamma^{3}\right)^{2}}, \\
D^{q q}=\frac{(3-2 \gamma)^{2}(1-c-\psi) \psi}{5-2 \gamma-4 \gamma^{2}+2 \gamma^{3}}, \\
W^{q q}=\frac{(3-2 \gamma)^{2}(1-c-\psi)^{2}}{2\left(5-2 \gamma-4 \gamma^{2}+2 \gamma^{3}\right)} .
\end{gathered}
$$

\section{p-q game}

We now consider the third situation wherein Firm 0 and Firm 1 simultaneously determine the price and quantity, respectively. Consumer surplus is given by

$$
C S=\frac{\left(1-p_{0}\right)^{2}+\left(1-\gamma^{2}\right) q_{1}^{2}}{2} .
$$

On calculating the first-order conditions for both firms' maximization problems, the reaction functions are given by

$$
\begin{gathered}
R_{0}^{p q}\left(q_{1}\right)=c+t, \\
R_{1}^{p q}\left(p_{0}\right)=\frac{1-\gamma+\gamma p_{0}-c-t}{2\left(1-\gamma^{2}\right)}
\end{gathered}
$$

From these reaction functions, we obtain the equilibrium price for Firm 0 and equilibrium quantity for Firm 1:

$$
\begin{gathered}
p_{0}^{p q}=c+t, \\
q_{1}^{p q}=\frac{1-c-t}{2(1+\gamma)} .
\end{gathered}
$$

By substituting the above equilibrium price for Firm 0 and equilibrium quantity for Firm 1 into Equation (1) and using $\mathrm{d} W / \mathrm{d} t=0$, we obtain the equilibrium environmental tax as

$$
t^{p q}=\psi-\frac{(1-\gamma)(1-c-\psi)}{5+3 \gamma} .
$$

Since the second term on the right-hand side of the above equation is negative, Equation (4) implies that the optimal environmental tax rate is less than the marginal social damage cost. Using Equation (4), we obtain the following results:

$$
\omega^{p q}=\frac{(7+\gamma)(3+\gamma)^{2}(1-c-\psi)^{2}}{2(1+\gamma)(5+3 \gamma)^{2}},
$$




$$
\begin{gathered}
\pi_{1}^{p q}=\frac{(1-\gamma)(3+\gamma)^{2}(1-c-\psi)^{2}}{(1+\gamma)(5+3 \gamma)^{2}}, \\
D^{p q}=\frac{(3+\gamma)^{2}(1-c-\psi) \psi}{(1+\gamma)(5+3 \gamma)^{2}}, \\
W^{p q}=\frac{(3+\gamma)^{2}(1-c-\psi)^{2}}{2(1+\gamma)(5+3 \gamma)} .
\end{gathered}
$$

\section{q-p game}

We consider the fourth situation wherein Firm 0 and Firm 1 simultaneously determine the quantity and price, respectively. Consumer surplus is given by

$$
C S=\frac{\left(1-\gamma^{2}\right) q_{0}^{2}+\left(1-p_{1}\right)^{2}}{2} .
$$

Considering the firms' maximization problems, the reaction functions are given by

$$
\begin{gathered}
R_{0}^{q p}\left(p_{1}\right)=\frac{1-c-t}{1+\gamma}, \\
R_{1}^{q p}\left(q_{0}\right)=\frac{1-\gamma q_{0}+c+t}{2} .
\end{gathered}
$$

From these reaction functions, we obtain the equilibrium quantity for Firm 0 and the equilibrium price for Firm 1:

$$
\begin{gathered}
q_{0}^{q p}=\frac{1-c-t}{1+\gamma} \\
p_{1}^{q p}=\frac{1+(1+2 \gamma)(c+t)}{2(1+\gamma)}
\end{gathered}
$$

By substituting the above equilibrium quantity for Firm 0 and the equilibrium price for Firm 1 into Equation (1) and using $\mathrm{d} W / \mathrm{d} t=0$, we obtain the equilibrium environmental tax as

$$
t^{q p}=\psi-\frac{(1+2 \gamma)(1-c-\psi)}{5+4 \gamma} .
$$

Since the second term on the right-hand side of the above equation is negative, Equation (5) implies that the optimal environmental tax rate falls short of the marginal social damage cost.

Using Equation (5), we obtain the following results:

$$
\begin{gathered}
\omega^{q p}=\frac{9(7+8 \gamma)(1-c-\psi)^{2}}{2(5+4 \gamma)^{2}}, \\
\pi_{1}^{q p}=\frac{9(1-c-\psi)^{2}}{(5+4 \gamma)^{2}}, \\
D^{q p}=\frac{9 \psi(1-c-\psi)}{5+4 \gamma}, \\
W^{q p}=\frac{9(1-c-\psi)^{2}}{2(5+4 \gamma)} .
\end{gathered}
$$

\section{Comparisons}

Based on the results presented in the previous section, we compare the four situations. We first derive the rela- 
tionship among the equilibrium emission taxes in these four situations:

$$
\begin{gathered}
\psi>t^{p q} \geq t^{q q}>t^{p p}>t^{q p} \quad \text { if } 0<\gamma \leq \frac{1}{2}, \\
\psi>t^{q q}>t^{p q}>t^{p p}>t^{q p} \quad \text { if } \frac{1}{2}<\gamma<1 .
\end{gathered}
$$

From Equations (6) and (7), we can obtain the following propositions.

\section{Proposition 1.}

The optimal emission tax is lower than the marginal social damage cost for any of the situations in a mixed duopoly regardless of the degree of substitutability of goods.

The above result is in line with the results obtained previously that indicate that the emission tax should be set lower than marginal damage cost whether the firms choose price or quantity. Equations (6) and (7) also indicate as follows. If the substitutability of goods is low, the equilibrium emission tax is the highest when the public firm chooses price and the private firm chooses quantity. On the other hand, if the substitutability of goods is high, the equilibrium emission tax is the highest when both firms choose quantities.

Next, we compare the equilibrium social welfare values:

$$
W^{p p}>W^{q p}>W^{p q}>W^{q q} .
$$

We summarize this result as follows.

\section{Proposition 2.}

Social welfare is the highest when both the public firm and the private firm simultaneously choose prices.

The results imply that the emission tax should be set sufficiently low. Although a sufficiently low emission tax leads to environmental damage, Bertrand competition can increase social welfare.

\section{Conclusion}

This paper compares price and quantity competition in a mixed duopoly with emission tax. We find that social welfare is the highest when both public and private firms choose prices since the emission tax is then sufficiently lower than the marginal social damage. Although a sufficiently low emission tax deteriorates the environment, Bertrand competition can increase social welfare.

\section{References}

[1] Barcena-Ruiz, J.C. and Garzon, M.B. (2006) Mixed Oligopoly and Environmental Policy. Spanish Economic Review, 8, 139-160. http://dx.doi.org/10.1007/s10108-006-9006-y

[2] Beladi, H. and Chao, C.C. (2006) Does Privatization Improve the Environment? Economics Letters, 93, 343-347. http://dx.doi.org/10.1016/j.econlet.2006.06.005

[3] Kato, K. (2006) Can Allowing to Trade Permits Enhance Welfare in Mixed Oligopoly? Journal of Economics, 88, 263283. http://dx.doi.org/10.1007/s00712-006-0206-6

[4] Naito, T. and Ogawa, H. (2009) Direct versus Indirect Environmental Regulation in a Partially Privatized Mixed Duopoly. Environmental Economics and Policy Studies, 10, 87-100.

[5] Ohori, S. (2006) Optimal Environmental Tax and Level of Privatization in an International Duopoly. Journal of Regulatory Economics, 29, 225-233. http://dx.doi.org/10.1007/s11149-006-6037-0

[6] Ohori, S. (2012) Environmental Tax and Public Ownership in Vertically Related Markets. Journal of Industry, Competition and Trade, 12, 169-176. http://dx.doi.org/10.1007/s10842-010-0093-y

[7] Matsumura, T. and Ogawa, A. (2012) Price versus Quantity in a Mixed Duopoly. Economic Letters, 116, 174-177. http://dx.doi.org/10.1016/j.econlet.2012.02.012

[8] Nakamura, Y. (2013) Social Welfare under Quantity Competition and Price Competition in a Mixed Duopoly with Network Effects: An Analysis. Theoretical Economics Letters, 3, 211-215. http://dx.doi.org/10.4236/tel.2013.34035

[9] Requate, T. (2006) Environmental Policy under Imperfect Competition. In: Tietenberg, T. and Folmer, H., Eds., The International Yearbook of Environmental and Resource Economics 2006/2007. A Survey of Current Issue. Edward Elgar, Cheltenham, 120-207. http://dx.doi.org/10.4337/9781847200235.00011

[10] Barnett, A.H. (1980) The Pigouvian Tax Rule under Monopoly. American Economic Review, 70, 1037-1041. 